\title{
Aspectos histoquímicos e imunoistoquímicos nos neoplasmas do sistema nervoso periférico
}

[Histochemical and immunohistochemical features of peripheral nerve neoplasms]

\author{
A.M. Viott ${ }^{1}$, A.T. Ramos $^{1}$, M.A. Inkelmann ${ }^{2}$, G.D. Kommers ${ }^{1}$, D.L. Graça ${ }^{1 *}$ \\ ${ }^{1}$ Universidade Federal de Santa Maria \\ Av. Roraima, 1000 \\ 97105-900 - Santa Maria, RS \\ ${ }^{2}$ Médico veterinário autônomo
}

\begin{abstract}
RESUMO
Doze casos de tumores do sistema nervoso periférico, sete schwannomas e cinco neurofibromas foram diagnosticados entre 1964 e 2004, em caninos e bovinos. Histologicamente, as células predominantes nos schwannomas eram fusiformes organizavam-se em paliçada ou em feixes aleatórios. Nos neurofibromas as células neoplásicas eram fusiformes e se originavam da periferia dos nervos formando ninhos e feixes. $\mathrm{O}$ tecido conjuntivo era mais abundante nos neurofibromas e os colágenos dos tipos I e III eram os principais constituintes desses neoplasmas. Os neurofibromas foram caracterizados por uma concentração alta e difusa de mastócitos, provavelmente devido à origem das células neoplásicas do perineuro e epineuro. A coloração de AgNOR não se mostrou eficiente como indicador de prognóstico nos neoplasmas analisados. Imunoistoquímicamente houve forte marcação para vimentina (100\%) e S100 $(100 \%)$ em ambos os tipos de tumor. A maioria dos schwannomas (75\%) foi positiva para a proteína ácida fibrilar glial; os neurofibromas só apresentaram marcação nas células de Schwann dos fascículos nervosos.
\end{abstract}

Palavras-chave: canino, bovino, neoplasmas dos nervos periféricos, schwannomas, neurofibromas

\section{ABSTRACT}

A retrospective study of peripheral nerve tumors was made from 1964 to 2004. The tumors summed up 12, being seven schwannomas and five neurofibromas. Schwannomas were composed of spindle-shaped cells either in a palisading pattern or random bundles loosely textured and neurofibromas by spindle cells. The connective tissue components were more prevalent in neurofibromas with a characteristic deployment of collagens type I and III. In AgNOR techniques, both benign and malignant schwannomas and neurofibromas did not show differences. Mast cells stained by toluidine blue were more prevalent in neurofibromas which are rich in reactive endoneurium. Schwannomas (100\%) and neurofibromas $(100 \%)$ were positive for vimentin and S100 protein, so they prove to be reliable for the diagnosis of peripheral nerve tumors. GFAP marked cells were found in three schwannomas and in Schwann cells within neurofibromas.

Keywords: canine, bovine, neoplasms of peripheral nerves, schwannomas, neurofibromas

\section{INTRODUÇ̃̃O}

Os tumores dos nervos periféricos (TNP) originam-se das células de Schwann, fibroblastos perineurais, ou ambos, e são classificados segundo a Organização Mundial da Saúde em: schwannomas, neurofibromas, perineuromas e tumores malignos de bainha do nervo periférico (TMBNP). Todos são raros e acometem caninos, felinos, bovinos, eqüinos, suínos e caprinos. Em cães e humanos, os tumores malignos do SNP apresentam um padrão histológico variável e

Recebido em 21 de março de 2007

Aceito em 21 de agosto de 2007

Autor para correspondência (corresponding author)

E-mail: dlgraca@smail.ufsm.br 
diferenciações divergentes como: epitelióide, rabdomioblástica, cartilaginosa, óssea, angiomatosa e glandular (Woodruff et al., 2000; Zamecnik e Michal, 2001).

O uso de critérios morfológicos para o diagnóstico dos TNP em alguns casos é difícil. Isso se aplica não só aos neoplasmas malignos, mas também aos benignos, quando os tumores se originam em locais não usuais (LeCouter, 2001). $\mathrm{O}$ uso de técnicas histoquímicas e imunoistoquímicas contribui na determinação da diferenciação e da histogênese do tumor, além de auxiliar no seu diagnóstico e na sua caracterização (Koestner e Higgins, 2002). O presente trabalho teve como objetivo a aplicação e avaliação de técnicas histoquímicas e imunoistoquímicas nos TNP. Essas técnicas foram aplicadas no intuito de auxiliar no diagnóstico e na avaliação morfológica desses neoplasmas.

\section{MATERIAL E MÉTODOS.}

As amostras foram obtidas no arquivo de blocos do Laboratório de Patologia da Universidade Federal de Santa Maria entre 1964 e 2004. Além da casuística, foram levantados dados de resenha e clínicos que incluíam espécie, sexo, raça, idade, localização, sinais clínicos, presença de metástases, tempo de evolução e aspecto macroscópico quando mencionados.

Secções de $5 \mu \mathrm{m}$ foram coradas com hematoxilina-eosina (Culling et al., 1985). Cada tumor de sistema nervoso periférico foi previamente analisado e o grau de malignidade baseou-se na atipia e no pleomorfismo celular. Os neoplasmas foram divididos em quatro grupos: schwannomas benignos, schwannomas malignos, neurofibromas benignos e neurofibromas malignos. Essa classificação prévia permitiu uma melhor análise do resultado da técnica de AgNOR.

Cortes de $5 \mu \mathrm{m}$ de cada neoplasma foram corados pelo kit Easy Path ${ }^{1}$ para Tricrômico de Masson, de acordo com as instruções do fabricante. Os cortes histológicos foram analisados, e a presença de tecido conjuntivo foi observada e classificada em quatro graus:

${ }^{1}$ Easy Path, Erviegas - São Paulo, Brasil. ausente $(-)$, leve $(+)$, moderada $(++)$ e acentuada $(+++)$.

Cortes de $5 \mu \mathrm{m}$ foram corados por uma hora em uma solução de sírius "red" a $0,1 \%$ dissolvida em ácido pícrico. Após, as lâminas foram lavadas rapidamente em água corrente e contra coradas em uma solução de hematoxilina de Harris por $6 \mathrm{~min}$. Depois de montadas, as lâminas foram analisadas em microscópico óptico convencional com o auxilio de dois filtros polarizadores que promoviam a birrefringência no colágeno corado (Montes e Junqueira, 1991).

Seções de $5 \mu \mathrm{m}$ foram submetidas à coloração de AgNOR segundo Rech et al. (2004). Para definir o número de $\mathrm{AgNOR}$, foram contados os pontos pretos no interior dos núcleos em cem células tumorais em campos aleatórios e representativos de maior aumento (1000x) e divididos por cem (Rech, 2003). A analise estatística dos cortes de AgNOR foi realizada conforme o programa SAS, e o teste utilizado foi o teste Tukey.

Cortes de $5 \mu \mathrm{m}$ dos neoplasmas foram imersos em solução de toluidina a $0,1 \%$ por dois minutos (Culling et al., 1985). Foram coletados fragmentos do nervo trigêmio de um bovino e do plexo braquial de um cão para serem usados como controle na quantificação dos mastócitos nos neoplasmas. Para a contagem do número de mastócitos foram analisados 10 campos aleatórios com objetiva de 40x.

Amostras dos neoplasmas foram processadas rotineiramente para a realização da técnica de imunoistoquímica. Para a imunomarcação da vimentina, S100, proteína acida fibrilar glial (GFAP) em neurofibromas e schwannomas foram utilizados os seguintes anticorpos: a) "monoclonal" anti-vimentina clone $\mathrm{V}^{2}$ de camundongo na diluição de $1: 100$; b) "policlonal" anti-S1002 de coelho na diluição $1: 200$; c) "monoclonal" anti-GFAP ${ }^{2}$ humano na diluição 1:100 respectivamente. Cortes de $3 \mu \mathrm{m}$ foram submetidos ao bloqueio da peroxidase endógena com peróxido de hidrogênio a 3\% por $20 \mathrm{~min}$. A recuperação antigênica foi realizada em forno de microondas com TRIS-EDTA ( $\mathrm{pH}$ $9,0)$ por $10 \mathrm{~min}$. O bloqueio dos sítios inespecíficos foi realizado com leite em pó

\footnotetext{
${ }^{2}$ Dako Cytomation - São Paulo, Brasil.
} 
desnatado a 5\% em PBS por 30min. A incubação com o anticorpo primário, diluído em diluente de anticorpo $^{3}$, foi realizada overnight em câmara úmida. As seções foram incubadas com anticorpo secundário biotinilado ${ }^{3}$ por $35 \mathrm{~min}$ em temperatura ambiente. Seguiu-se a incubação com complexo estreptoavidina-peroxidase ${ }^{4}$ por $35 \mathrm{~min}$ em temperatura ambiente. As lavagens entre as principais etapas foram realizadas com PBS pH 7,0. A revelação foi executada com $\mathrm{DAB}^{5}$. As seções foram contracoradas com hematoxilina de Harris por $1 \mathrm{~min}$, desidratadas, clarificadas e montadas com resina sintética. As lâminas foram avaliadas segundo sua marcação positiva ou negativa.

\section{RESULTADOS}

Dos 12 tumores diagnosticados, nove foram submetidos às analises histoquímicas e imunoistoquímicas. Os schwannomas corresponderam ao maior grupo de neoplasmas do SNP (7/12), quatro malignos e um benigno. Todos foram diagnosticados em cães com média de idade de 7,8 anos e a raça mais afetada foi a Pastor Alemã (4/7). Quanto à localização anatômica, os tumores ocorreram principalmente nos membros. Somente em um dos casos houve metástases, e estas se localizaram no pulmão. Quanto ao tempo de evolução, nos casos informados (5/7), variou entre 21 dias e um ano. Os sinais clínicos foram: claudicação do membro afetado, deficiência neurológica e proprioceptiva do reflexo flexor além de sensibilidade superficial e profunda diminuídas.

Os neurofibromas corresponderam ao menor grupo $(5 / 12)$ de neoplasmas do SNP, e foram diagnosticados em bovinos (3/5) e caninos (2/5), dois eram malignos e três eram benignos. Dos bovinos, em dois casos o sexo do animal não foi informado, e um foi diagnosticado em fêmea. Um dos animais tinha oito anos e em dois protocolos, a idade não foi informada. O tempo de evolução foi de aproximadamente um ano. $\mathrm{O}$ sinal clínico mais citado nos casos de neurofibroma era de hiperestesia acentuada. Um cão macho Cocker, de seis anos, apresentou um neurofibroma no membro anterior esquerdo, com

\footnotetext{
${ }^{3}$ Dako antibody diluent - São Paulo, Brasil.

${ }^{4}$ Dako LSAB+Kit Peroxidase - São Paulo, Brasil.

${ }^{5}$ SIGMA D5637-10G - Porto Alegre, Brasil.
}

tempo de evolução de um ano e recidiva seis meses após a cirurgia.

Os schwannomas eram invasivos, mediam de 2 a $7 \mathrm{~cm}$ de diâmetro, e caracterizaram-se como estruturas ovais brancas ou avermelhadas com ou sem envolvimento macroscópico de um fascículo nervoso. Os tumores eram firmes e ao corte apresentavam-se esbranquiçados ou amarelados. Os neurofibromas caracterizavam-se por estruturas nodulares ou elípticas que variavam de $1 \mathrm{~mm}$ a $25 \mathrm{~cm}$ de diâmetro. Essas nodulações eram brancas, firmes e/ou moles. Ao corte os neoplasmas tinham um aspecto brancoacinzentado, liso, brilhante e homogêneo.

Microscopicamente, os schwannomas caracterizavam-se por proliferação neoplásica altamente celular composta de células fusiformes que se arranjavam ora em paliçada (padrão Antoni tipo A) ora em ninhos e feixes dispostos em vários sentidos (Fig. 1A). Em um dos tumores havia áreas pouco celulares onde as células organizavam-se numa textura frouxa envoltas por uma matriz mixóide basofílica (padrão Antoni tipo B). O citoplasma das células apresentava-se eosinofílico e indistinto, os núcleos fusiformes ou ovais com um a três nucléolos evidentes. Células multinucleadas eram freqüentes, principalmente quando havia anisocitose acentuada. Em um dos schwannomas observou-se diferenciação óssea. As mitoses estavam acentuadas, mais de cinco por campo de grande aumento e o pleomorfismo celular e nuclear de moderado a acentuado. Focos de hemorragia e extensas áreas de necrose eram freqüentes e infiltrado linfoistioplasmocítico difuso moderado estava presente em todos os casos.

Os neurofibromas caracterizaram-se por proliferação neoplásica infiltrativa de células fusiformes, com núcleos basofílicos, ovóides a fusiformes e levemente curvados com um a três nucléolos evidentes. As células neoplásicas multiplicavam-se a partir da periferia dos nervos e formavam feixes e ninhos (Fig. 1B). O pleomorfismo celular e nuclear era de moderado a acentuado com formas nucleares aberrantes e mitoses raras a moderadas. Hiperplasia e hipertrofia dos fascículos nervosos eram constantes, os corpos neuronais raros, e os infiltrados inflamatórios linfohistioplasmocíticos e neutrofílicos moderados 
localizavam-se principalmente na derme superficial.

O método do tricrômico de Masson permitiu avaliar o tecido conjuntivo fibroso nos schwannomas e neurofibromas. Nos schwannomas observava-se proliferação discreta entre as células organizadas em paliçada; por vezes, uma fina camada de tecido conjuntivo envolvia as células neoplásicas. Em todos os casos o tecido conjuntivo estava distribuído uniformemente na cápsula do tumor. Nos neurofibromas o tecido conjuntivo era visto de forma moderada a acentuada no perineuro. No endoneuro, as fibras de tecido conjuntivo estavam dispostas em pequenos feixes aleatórios, numa forma difusa de moderada a acentuada (Fig. 1C).

As regiões organizadoras nucleolares argirofílicas (AgNOR) coraram-se como pontos pretos ou marron-escuros. A média $( \pm D P)$ de contagem de AgNOR em 100 células nos schwannomas benignos foi de $1,66 \pm 0,26$ e nos malignos de 1,78 $\pm 0,09$ (Fig. 1D). Nos neurofibromas classificados como benignos a média foi de $1,72 \pm 0,04$ e nos malignos de $1,83 \pm 0,13$. As médias de AgNOR dos neoplasmas benignos e malignos de ambos os tumores não foram diferentes $(\mathrm{P}>0,05)$.

Por meio da técnica do picrosirius red observouse que nos schwannomas havia intensa proliferação de fibras de colágeno tipo I na cápsula do neoplasma e leve entre as células em paliçada e nas áreas de padrão mixomatoso. A presença de colágeno tipo III variava de discreta a acentuada e, quando presente, este estava disposto em feixes curtos entre as fibras colágenas tipo I e, algumas vezes, sozinho entre as células tumorais (Fig. 1E). Os neurofibromas apresentaram grande quantidade de fibras de colágeno tipo I principalmente no epineuro e perineuro dos nervos de maior calibre e, também, em menor quantidade, no endoneuro. O colágeno tipo III era moderado no endoneuro e perineuro (Fig. 1F).

Por meio do azul de toluidina foram analisados oito neoplasmas, quatro neurofibromas e quatro schwannomas. Nos nervos dos animais normais o número médio de mastócitos foi de dezesseis por campo de grande aumento nos bovinos, e de três em caninos. Os neurofibromas de cães e bovinos apresentaram um grande número de mastócitos, em média $38,75 \pm 10,4$ por neoplasma. Já os schwannomas de cães apresentaram uma variação média de 10 mastócitos por campo de grande aumento $\pm 10,6$.

As células neoplásicas dos schwannomas e neurofibromas foram fortemente positivas para a vimentina (4/4 e 5/5) (Fig. $2 \mathrm{~A}$ e $2 \mathrm{~B}$ ) e para a proteína $\mathrm{S} 100(4 / 4$ e 5/5) (Fig. 2C e 2D). Com relação à GFAP, três schwannomas foram positivos (3/4) e um (1/4) não apresentou marcação. A marcação era difusa acentuada (1/3) ou multifocal aleatória $(2 / 3)$ em pequenos grupos de células (Fig. 2E). Os neurofibromas não apresentaram marcação por GFAP nas células neoplásicas. Somente as células de Schwann, que estavam presentes nos fascículos nervosos, foram marcadas (Fig. 2F).

\section{DISCUSSÃO}

As bainhas de tecido conjuntivo dos nervos periféricos são formadas por diversos tipos celulares, o que determina a formação de diferentes neoplasmas: schwannomas, neurofibromas, perineuromas e tumores malignos do sistema nervoso periférico (SNP) (Zamecnik e Michel, 2001), sendo que dentre essas os mais freqüentes são os schwannomas e os neurofibromas (Koestner e Higgins, 2002). A ocorrência dos schwannomas em cães e de neurofibromas em bovinos e caninos neste estudo é semelhante às informações epidemiológicas desses neoplasmas, sendo os neurofibromas menos freqüentes nos caninos (Pumarola et al., 1996; Koestner e Higgins, 2002).

A idade média dos cães com schwannomas foi muito semelhante à observada por LeCouter (2001) que analisou 43 schwannomas em cães entre 5 e 12 anos com idade média de oito anos, sugerindo que os schwannomas são mais freqüentes em cães adultos e idosos. Não foi possível avaliar a média de idade dos animais com neurofibroma devido à falta de informações obtidas nos protocolos, mas, ao contrário do que ocorre com os schwannomas, parece não haver predisposição etária para esses neoplasmas (Woodruff et al., 2000). 

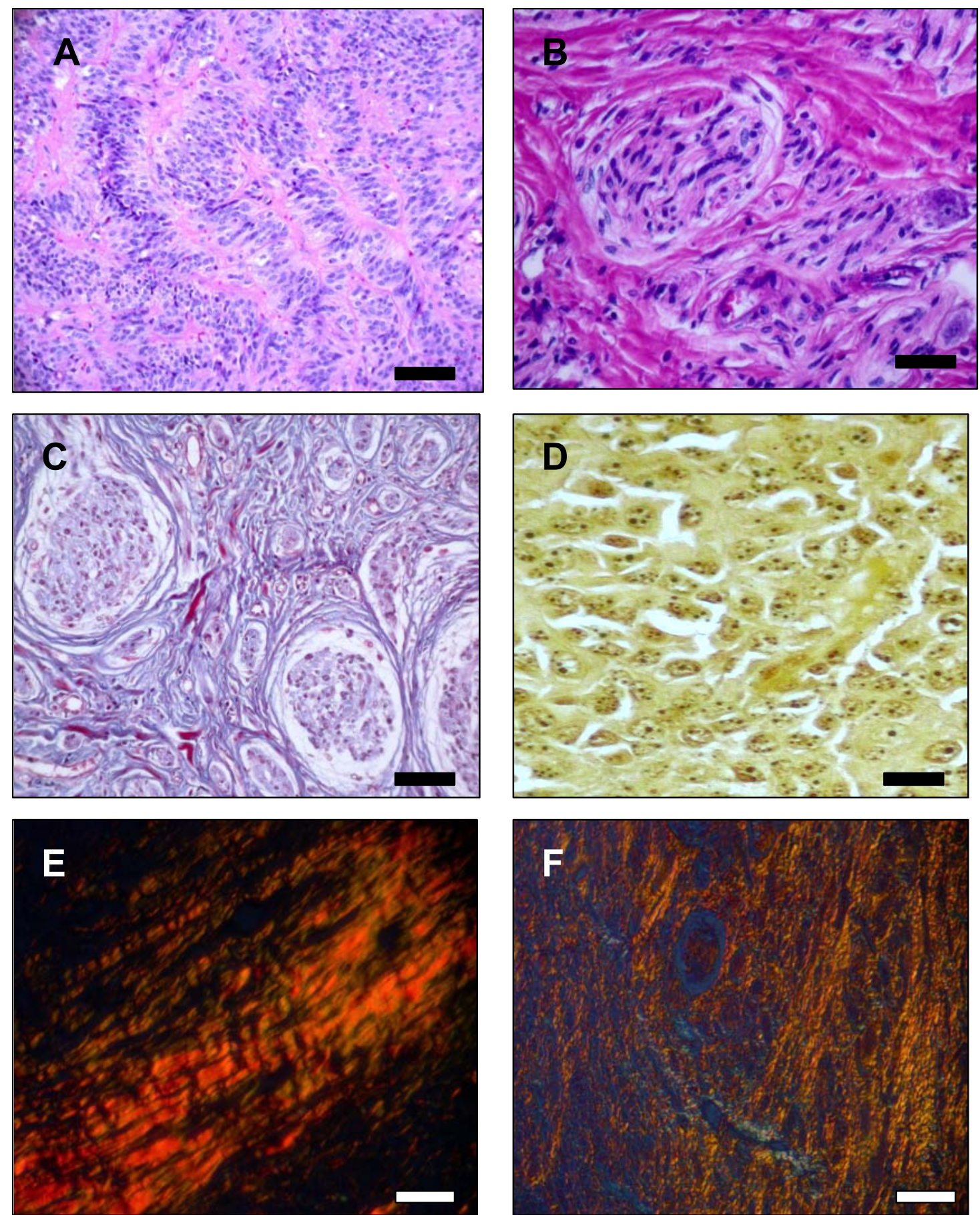

Figura 1. A) Schwannoma em olho de cão: células neoplásicas fusiformes em paliçada. HE, barra $30 \mu \mathrm{m}$. B) Neurofibroma em fígado de bovino; as células neoplásicas estão arranjadas em feixes e ninhos, que envolvem e segmentam os axônios. HE, barra $50 \mu \mathrm{m}$. C) Neurofibroma em fígado de bovino: o tecido conjuntivo entremeado às células neoplásicas que circundam os axônios está corado de azul. tricrômico de Masson, barra $30 \mu \mathrm{m}$. D) Schwannoma pouco diferenciado em plexo braquial de cão: AgNOR 1,87, barra $20 \mu \mathrm{m}$. E) Schwannoma em plexo braquial de cão: há intensa coloração do colágeno tipo I (vermelho), o colágeno tipo III (esverdeado) é escasso, picrosírius red, barra $50 \mu \mathrm{m}$. F) Neurofibroma em fígado de bovino: observa-se intensa coloração do colágeno tipo I (vermelho e amarelo) e moderadas fibras de colágeno tipo III. Picrosírius red, barra $30 \mu \mathrm{m}$. 

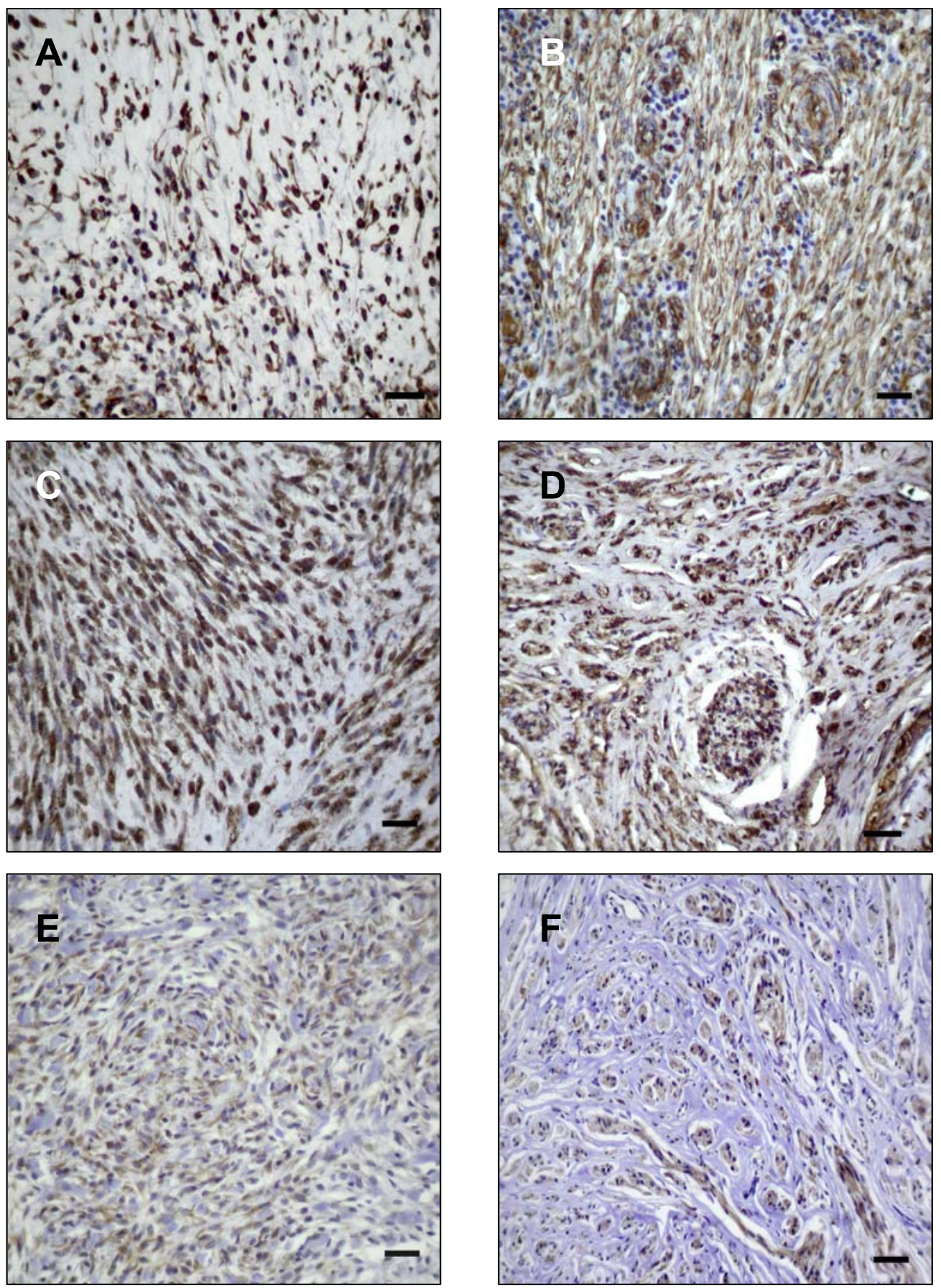

Figura 2. A) Schwannoma em plexo braquial de cão: observa-se forte marcação no citoplasma das células e seus prolongamentos pelo anticorpo anti-vimentina. IHQ, barra $30 \mu \mathrm{m}$. B) Neurofibroma em língua de bovino: as células neoplásicas do neurofibroma estão imunomarcadas pelo anticorpo antivimentina. IHQ, barra $30 \mu \mathrm{m}$. C) Schwannoma

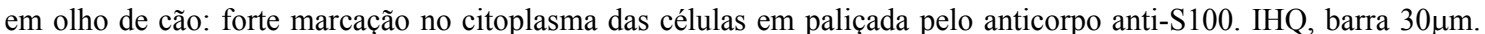
D) Neurofibroma em fígado de bovino: as células neoplásicas estão marcadas pelo anticorpo anti-S100. Observar que

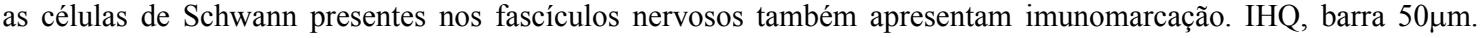
E) Schwannoma na região cervical de um cão: marcação irregular no citoplasma das células neoplásicas pelo anticorpo anti-GFAP. IHQ, barra $30 \mu \mathrm{m}$. F) Neurofibroma em fígado de bovino; ausência de marcação das células neoplásicas do neurofibroma pelo anticorpo anti-GFAP; nos fascículos nervosos há marcação das células de Schwann. IHQ, barra $50 \mu \mathrm{m}$. 
Segundo LeCouter (2001) e Koestner e Higgins (2002) não há predileção racial e sexual para os neoplasmas de SNP. Devido ao reduzido número de neoplasmas encontrados nos nossos arquivos não foi possível avaliar essa característica. Os sinais clínicos dos schwannomas eram iguais aos descritos por Pumarola et al., (1996) que ainda citam depressão, desorientação, ataxia, atrofia muscular e mais de um deficit postural quando ocorre compressão medular intra ou extradural.

No presente estudo, os schwannomas foram mais freqüentes nos membros, afetando nervos distais. LeCouter (2001) citou que esses neoplasmas são mais comuns no canal vertebral diferentemente de Koestner e Higgins (2002), que observaram maior freqüência de schwannomas nos nervos que formam o plexo braquial, lombossacral e finalmente nos nervos periféricos distais. É freqüente a invasão medular e metástase pulmonar nos schwannomas pouco diferenciados, principalmente quando os neoplasmas se localizam no plexo braquial (Koestner e Higgins, 2002). A distribuição dos neurofibromas foi ampla, sem predileção por um sítio definido. Segundo a literatura, os neurofibromas têm disposição semelhante à observada nos schwannomas, localizando-se ao longo do curso de nervos de pequeno e grande calibre (Koestner e Higgins, 2002).

O grau histológico é um parâmetro importante para determinar o prognóstico e a escolha do tratamento pelo clínico (LeCouter, 2001). Nos schwannomas havia variação morfológica moderada, indicando um prognostico reservado. A presença de células ovais, observadas em alguns cortes indica pouca diferenciação das células neoplásicas (Chijiwa et al., 2004). Um dos schwannomas apresentou diferenciação óssea. Além desse padrão os schwannomas também podem apresentar focos únicos ou múltiplos de diferenciação cartilaginosa, mucóide, glandular, melanótica e granular (Patnaik et al., 1984; Kuwamura et al., 1998; Koestner e Higgins, 2002; Chijiwa et al., 2004). A formação celular observada nos neurofibromas foi semelhante à descrita por outros autores, mas os melanócitos que são freqüentes nesses neoplasmas (Ushigone et al., 1986; Woodruff et al., 2002) não foram observados.

A presença do infiltrado inflamatório linfoistioplasmocitário em ambos os tumores deve-se ao fato de as células tumorais poderem ser reconhecidas pelo sistema imune devido à expressão de antígenos específicos. Esses antígenos são produzidos durante a mutação dos genes celulares. Essas mutações produzem proteínas anormais que acabam sendo expressas na membrana plasmática induzindo uma resposta imune mononuclear (Cullen et al., 2002).

As bainhas dos nervos periféricos são compostas por células de Schwann, células perineurais e fibroblastos. Esses últimos estão presentes no perineuro, epineuro e endoneuro (Cavanagh, 1990; Zamecnick e Michal, 2001) como componentes neoplásicos ou não (Zamecnick e Michal, 2001). O tecido conjuntivo foi mais proeminente nos neurofibromas do que nos schwannomas. Essa diferença na quantidade de tecido conjuntivo expresso em cada tumor pode ser explicada pelos componentes celulares que formam os tumores. Os schwannomas são compostos unicamente por células de Schwann ao contrário dos neurofibromas que são formados por uma grande variedade de tipos celulares incluindo fibroblastos e células perineurais (Hirose et al., 1998). A presença e principalmente a quantidade de tecido conjuntivo nestes neoplasmas podem, portanto, auxiliar na diferenciação entre esses dois tumores.

A técnica do picrosirius permitiu qualificar os tipos de colágeno presentes nos neoplasmas analisados (Montes e Junqueira, 1991). Acreditase que a presença de colágeno tipo I e III e a ausência dos demais tipos de colágeno devem-se ao fato de os colágenos I e III serem constituintes normais do epineuro e do endoneuro enquanto que as demais fibras colágenas não são encontradas nesses tecidos (Montes e Junqueira 1991).

AgNORs são segmentos de DNA que transcrevem o RNA ribossomal. $\mathrm{O}$ número dessas regiões em cada núcleo está diretamente relacionado à proliferação celular e, portanto, pode servir como um indicador de potencial maligno de um tumor (Rech et al., 2004; Oliveira et al., 2005; Silva et al., 2006). Neste estudo, tanto os neurofibromas benignos e malignos quanto os schwannomas benignos e malignos tinham um alto número de AgNOR, presumivelmente devido à sua alta taxa de multiplicação celular. Não houve diferença estatística significativa entre os neoplasmas. 
Achado semelhante foi obtido por Chijiwa et al. (2004) que utilizaram o antígeno nuclear de proliferação celular (PCNA). Esses autores citam que devido à ineficácia dos marcadores de proliferação celular nos neoplasmas do SNP, devemos levar em conta a taxa de mitose e outros achados histopatológicos como a celularidade, anisocitose, atipia celular e focos de necrose para avaliar o comportamento do neoplasma.

Os mastócitos são vistos físiologicamente nos espaços endoneurais e seu número aumenta em qualquer forma de injúria ao SNP, mas a sua função ainda permanece desconhecida (Cavanagh, 1990). Os neurofibromas foram caracterizados por uma concentração alta e difusa de mastócitos. Nos schwannomas essa população celular era restrita a poucas áreas com algumas exceções. Essa marcada diferença entre os neoplasmas deve-se ao fato de os neurofibromas serem constituídos de tecido endoneural reativo onde os mastócitos são encontrados normalmente (Isaacson, 1976).

Imunoistoquimicamente, os TNP são geralmente positivos para a vimentina e S100, entretanto os tumores anaplásicos e heterogêneos tendem a ser negativos para S100. Alguns autores têm especulado que a ausência da marcação para S100 indica caráter de malignidade (Hirose et al., 1998; Koestner e Higgins, 2002), mas achado semelhante não foi observado neste trabalho. Em um estudo realizado por Mark et al. (1989), 60\% dos schwannomas não foram marcados pela proteína $\mathrm{S} 100$. Tal achado é muito semelhante ao de outros estudos imunoistoquímicos que envolvem o uso de S100 em schwannomas malignos. Isso sugere que a diferenciação dos schwannomas malignos de outros neoplasmas malignos de células fusiformes não deve ser limitada somente ao uso de S100, mas ao uso conjunto de outros marcadores das células de Schwann como, por exemplo, GFAP e o LEU 7.

Os TNP são neoplasmas pouco freqüentes tanto na rotina clínica quanto laboratorial, primeiramente por sua raridade e principalmente pela dificuldade no seu diagnóstico. As técnicas imunoistoquímicas utilizadas, na tentativa de melhor caracterização da origem desses neoplasmas (Garmatz et al., 2007), evidenciaram grande quantidade de tecido fibroso em neurofibromas e colágenos tipos I e III em ambos neoplasmas analisados.

Foi demonstrada alta incidência da imunorreatividade à GFAP $(75 \%)$ nos schwannomas e a ausência de marcação nas células neoplásicas dos neurofibromas, onde somente as células de Schwann presentes nos fascículos nervosos estavam marcadas. Achado semelhante foi obtido por Mark et al. (1989) que observaram marcação irregular de GFAP nos TNP analisados. O significado biológico dessa expressão variável da GFAP ainda não é claro. Esses autores observaram que os tumores mais próximos ao sistema nervoso central (SNC) apresentavam marcação mais acentuada, ao contrário daqueles localizados nas extremidades. Outros achados indicam que a ausência de imunomarcação possa estar correlacionada com o alto grau de anaplasia celular do tumor.

\section{CONCLUSÕES}

A técnica de AgNOR não foi eficiente na formulação do prognostico, indicando que avaliações criteriosas das células tumorais devem ser estabelecidas quando este se fizer necessário. Os achados da imunoistoquímica indicam que a caracterização imunoistoquímica dos TNP é dificultada pela grande diversidade de expressões antigênicas das células neoplásicas. $O$ diagnóstico imunoistoquímico, portanto, deve ser estabelecido levando-se em conta o uso de dois ou mais anticorpos que em conjunto devem ser avaliados para estabelecer a origem do tumor.

\section{REFERÊNCIA BIBLIOGRAFICA}

CAVANAGH, J.B. Peripheral Nervous system. In: WELLER, R.O. (Ed). nervous system, muscle and eyes. 3.ed. London: Churchill Livingstone, 1990. v.4, p.533-543.

CHIJIWA, K.; UCHIDA, K.; TATEYAMA, S. Immunohistochemical evaluation of canine peripheral nerve sheath tumors and other soft tissue sarcomas. Vet. Pathol., v.41, p.307-318, 2004.

CULLEN, J.M.; PAGE, R; MISDORP, W. An overview of cancer pathogenesis, diagnosis, and management. In: MEUTEN, D.J. (Ed). Tumors 
in Domestic Animals. Iowa: Iowa State, 2002. p.3-44.

CULLING, C.F.A.; ALLISON, R.T.; BARR, W.T. Cellular pathology technique. 4.ed. London: Butterworths, 1985. p.111-152

GARMATZ, B.C.; VIOTT, A.M.; SILVA, C.F. et al. Nódulos fibro-histiocíticos no baço de uma cadela: relato de caso. Arq. Bras. Med. Vet. Zootec., v.59, p.673-678, 2007.

HIROSE, T.; SCHEITHAUER, B.W.; SANO, T. Perineurial malignant peripheral nerve sheath tumor (MPNST): A clinicophatologic, immunohistochemical and ultrastructural study of seven cases. Am. J. Surg. Pathol., v.22, p.1368-1378, 1998.

ISAACSON, P. Mast cell in benign nerve sheath tumours. J. Pathol., v.119, p.193-196, 1976.

KOESTNER, A.; HIGGINS, R.J. Tumors of the nervous system. In: MEUTEN, D.J. (Ed). Tumors of domestic animals. 4.ed. Iowa: Iowa State, 2002. p.697-738.

KUWAMURA, M.; YAMATE, J.; KOTANI, T. et al. Canine peripheral nerve sheath tumor with eosinophilic cytoplasmic globules. Vet. Pathol., v.35, p.223-226, 1998.

LeCOUTER, R.A. Tumors of the nervous system. In: WITHROW, S.J.; MacEWEN, E.G. (Eds). Small clinical oncology. 3.ed. Philadelphia: W. B. Saunders, 2001. p.500-531.

MARK, G.H.; ROSEMBERG, A.E.; DICKERSIN, G.R. et al. Glial fibrillary acidic protein and keratin expression by benign and malignant nerve sheath tumors. Hum. Pathol., v.20, p.1089-1096, 1989.

MONTES, G.S.; JUNQUEIRA, L.C.U. The use of the picrosirius method for the study of the biopathology of collagen. Mem. Inst. Oswaldo Cruz, v.86, p.1-11, 1991.

OLIVEIRA, M.G.; LAUXEN, I.S.; MARTINS, $\mathrm{M}$. et al. Tongue squamous cell carcinoma: relationship between argyrophilic nucleolar organizer regions (AgNORs) and histophatologic grading. Appl. Canc. Res., v.25, p.20-24, 2005.

PATNAIK, A.K.; ERLANDSON, R.A.; LIEBERMAN, P.H. Canine malignant melanotic schwannomas: A light and electron microscopic study of two cases. Vet. Pathol., v.21, p.483-488, 1984.

PUMAROLA, M.; ANOR, S.; BORRAS, D. et al. Malignant epithelioid schwannoma affecting the trigeminal nerve of a dog. Vet. Pathol., v.33, p.434-436, 1996.

RECH, R.R. Mastócitos em condições normais e patológicas com ênfase nos mastocitomas de cães. 2003. 84f. Dissertação (Mestrado) Universidade Federal de Santa Maria, Santa Maria, RS.

RECH, R.R.; KOMMERS, G.D.; GRAÇA, D.L. et al. Mastocitoma cutâneo canino: Estudo de 45 casos. Arq. Bras. Med. Vet. Zootec., v.56, p.441448, 2004.

SILVA, A.E.; SANTOS, F.G.A.; CASSALI, G.D. Marcadores de proliferação celular na avaliação do crescimento do tumor sólido e ascítico de Ehrlich. Arq. Bras. Med. Vet. Zootec., v.58, p.658-661, 2006.

USHIGONE, S.; TAKAKUWA, T.; HYUGA, $M$. et al Perineurial cell tumor and the significance of the perineurial cell in neurofibroma. Acta Pathol. Jap., v.36, p.973987, 1986.

ZAMECNIK, M.; MICHAL, M. Perineurial cell differentiation in neurofibromas. report of eight cases including a case with composite perineuroma-neurofibroma features. Pathol. Res. Pract., v.197, p.537-544, 2001.

WOODRUFF, J.M.; KOUREA, H.P.; LOIS, D.N. et al. Tumors of cranial and peripheral nerves. In: KLEIHUES, P.; CAVENEE, W.K. (Eds). Pathology and genetics of tumors of the nervous system. Lyon: IARC, 2000. p.164-174. 